\title{
EDITORIAL
}

\author{
JOHN O'TOOLE AND PENNY BUNDY \\ Griffith University, Australia
}

\section{Be careful what you wish for}

Thirty years ago in Australia, one of the editors watched a theatre in education team demonstrate to an audience of teachers and drama students their latest early childhood participatory program about overcoming stereotypes, aimed at helping children to get over unreal and unnecessary fears of dragons and monsters. The arts philosopher Robert Witkin then led the team and the audience in deconstructing that program, revealing to everyone's surprise that while they were indeed successfully dismantling unhealthy stereotypes of nasty dragons, they were simultaneously reinforcing equally strongly a number of other powerful stereotypes - albeit rather more healthy ones: of caring parents, and other acceptable social norms. This had at least as much effect on the children as the team's almost opposite intentions. Witkin was able to point out the paradoxical importance and usefulness of stereotypes in our lives, and in the education of young children (Haseman 1981: 29-32). The net result in this case was a benevolent double whammy, but it is not always so. Remember all those cautionary fairy tales about hopeful fishermen and princesses whose magic wishes come back to bite them?

We are beginning this edition, as we did the last, with a challenge - this time, from one of the most experienced and distinguished workers and thinkers in applied theatre. James Thompson's essay, which led the last edition, and Tim Prentki and David Pammenter's, which leads this one, both pose a challenge to all those working in applied theatre and drama education with an aim of changing social conditions or people's lives. As Newton's third law reminds us, every action has an equal and opposite reaction, and the impressive results we often 
claim for our work in the field may come at a price somewhere else. One group's affirmation may predicate another's demoralization, as Thompson eloquently showed in the last edition. Prentki and Pammeter confront us in this edition with how easy it is to be seduced into believing we are offering a universal pedagogy of hope. As they pungently point out, personal hope is a very different, sometimes contradictory thing from hope for political and social change.

Journals like ours may sometimes unwittingly be complicit in this blinkered view of the effects of our medium, no matter how rigorously we demand corroborative literature and evidence, because by definition the unexpected is not in the literature, and evidence of the perhaps unseen reaction may not be collected, or even collectible. And, of course, we all want to publish and read about inspiring and successful projects.

We are, however, constantly seeking new ways to research and map our constantly changing and complex field, where the personal, social and political are so inextricably entangled. Our next two articles embrace that challenge, willingly 'inviting the entanglement', as Molly Mullen - a young researcher puts it, as she candidly and honestly invites us to share her own tangles in the web of three applied theatre projects. Björn Rasmussen takes a more broadly theoretical stance, using the increasingly popular methodology of practice-led research as the base of a proposition for a radically new ecological epistemology within which we can view and study what we do in a holistic way.

A more literal exploration of what we normally understand by the word 'ecology' is undertaken by Barry Freeman and Natalie Frijia in their reflections on their Rouge Park Project. In this, they used location theatre in a new national park actually within a major city to redefine for an audience the relationship between the urban and the natural. Both performance and reflections highlight some of the ethical implications and quandaries of the political and social decisions made by the planners.

To provide a breath of reassurance, Jennifer Cogswell and Debra McLaughlan remind us of why drama teachers are in this game: in quite simple ways, drama can illuminate, educate and inspire our understanding of history. For school students in particular, the past may be another country, but it is one in which, through the power of dramatic empathy, messages and meanings for the present can be revealed to them.

Finally, to give this edition of challenges a real sting in the tail, Monica Prendergast reflects on a challenge of quite a different sort to our expectations: one to any conventional notion of performance aesthetic, of theatre art itself. She analyses the experimental contemporary phenomenon or movement of 'misperformance' - in its way, a theatrical equivalent of the punk revolution. In a refreshingly entangled ethnography of performance, she reveals how failure itself can be an achievement, even one to be celebrated. As she notes, there are ethical implications here too, in terms of the performer's relationship with the audience.

\section{A NOTE TO POTENTIAL AUTHORS}

We are excited and gratified by the increasing number and quality of submissions of articles since this Intellect journal replaced the former Applied Theatre Researcher, and we encourage you to submit articles that fit our guidelines and conform to our requirements.

Yet again, we make a plea for authors to respect our policy of minimal necessary referencing. This is particularly important for early researchers to 
note, coming to this form of writing straight from or alongside postgraduate study. Copious referencing is necessary in writing to persuade or impress examiners, but for a peer audience it makes reading interrupted, fragmented and wearisome, and clutters up with padding the pages of what is necessarily a succinct genre of publication. Postgraduate work needs to be rewritten with the following principles of journal articles in mind. Your audience will assume that being accepted for publication in a journal of this standing gives you a set of credentials among your peers, so you should not strive to impress. Keep citations and quotations of others' work only to what is both relevant and necessary to validate a questionable or ambiguous assertion, or refer the reader to further reading crucial to understanding the point being made. Resist the temptation to display erudition, or reference an assertion of the 'grass is green (Smith and Jones 2013)' variety of the bleedingly obvious - that is, knowledge that is in the common currency of this domain - unless to challenge it. Our readers are your peers, who are at least familiar with the basics of both applied theatre and research methods, so terms like 'theatre for development', 'process drama', 'ethnography', 'reflective practice', 'triangulation', 'semi-structured interviews', 'member-checking' and other basic terminology - and the concepts they imply - are part of the common currency in the field, and do not need to be referenced with a string of (usually very recent) citations. In addition, avoid self-referencing unless further reading is crucial to understanding or validating the implications of the quotation. Just say it don't quote yourself saying it merely to deepen the gravitas.

\section{REFERENCE}

Haseman, B. (1981), Five Workshops - Drama: from Practice to Theory, Brisbane: Brisbane South Region Drama Project.

John O'Toole and Penny Bundy have asserted their right under the Copyright, Designs and Patents Act, 1988, to be identified as the authors of this work in the format that was submitted to Intellect Ltd. 


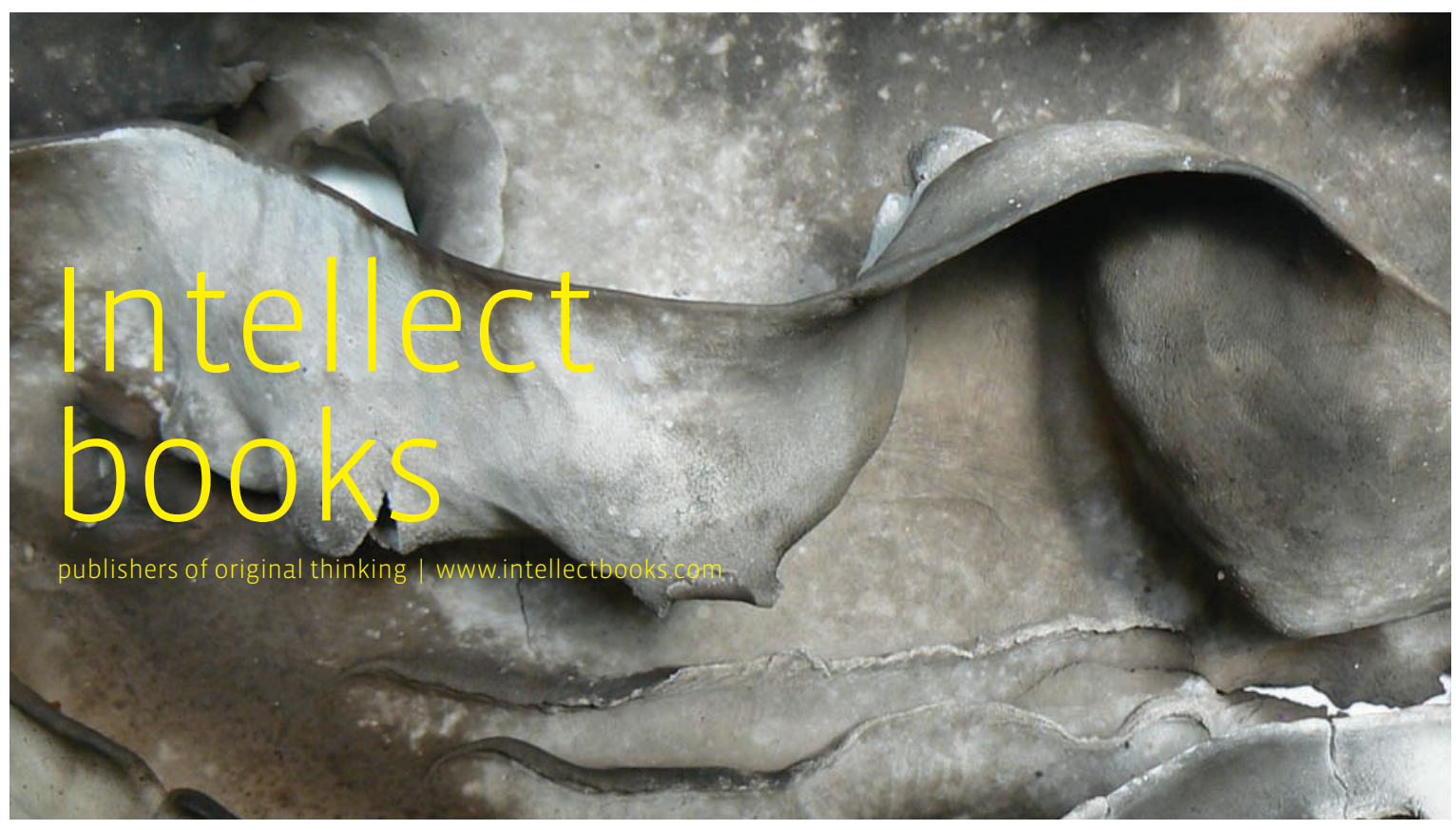

\section{Art as Research \\ Opportunities and Challenges}

\section{Edited by Shaun McNiff}

ISBN 978-1-78320-001-6 | 145pp

£12.95, \$18.00| 2013

Paperback | 230x170mm

eBook available

The new practice of art-based research uses art-making as a primary mode of enquiry rather than continuing to borrow research methodologies from other disciplines to study artistic processes. Drawing on contributions from arts therapies, education, history, organizational studies and philosophy, the essays critically examine unique challenges. These challenges include the personal and sometimes intimate nature of artistic enquiry and the complexities of partnership with social science (which has dominated applied arts research); how artistic discoveries are apt to emerge spontaneously, even contrary to plans and what we think we know; how truth can be examined through both fact and fiction as well as the interplay of objective and subjective experience; and ways of generating artistic evidence and communicating outcomes. Offering examples from all of the arts, this volume will be welcomed by researchers and students in many fields.

Shaun McNiff is university professor at Lesley University, USA, and author of Art-Based Research (1998) and many other books on the creative process.

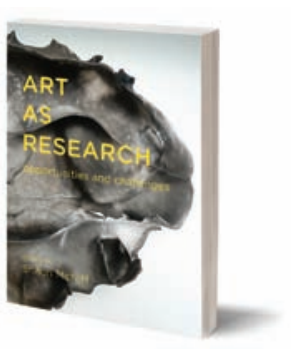

We are here to support your ideas and get them published. To send us your new book or journal proposal, please download a questionnaire from www.intellectbooks.com.

\section{0}

To view our catalogue or order our books and journals visit www.intellectbooks.com

Intellect, The Mill, Parnall Road, Fishponds, Bristol, BS16 3JG.

Tel: +44 (0) 1179589910

Fax: +44 (0) 1179589911 